\title{
Effective gender-based violence screening tools for use in primary health care settings in Afghanistan and Pakistan: a systematic review
}

J. Vogel

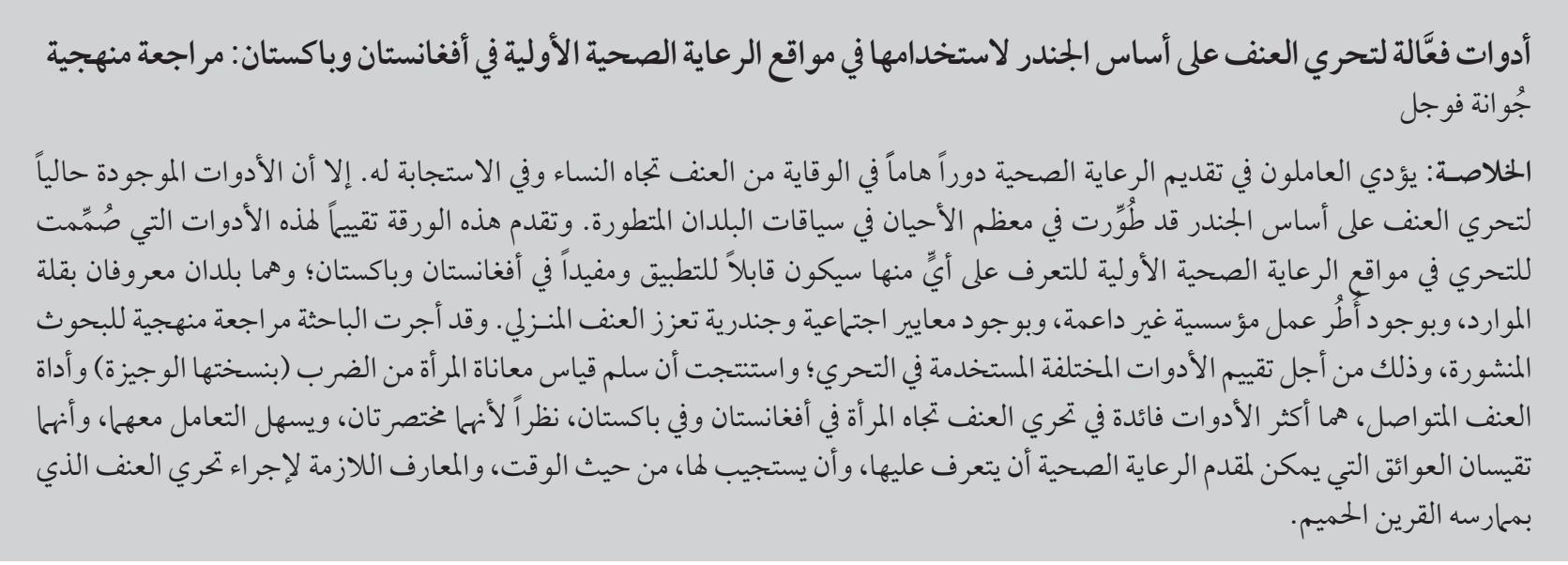

ABSTRACT Health care providers have an important role to play in the prevention and response to violence against women. However, the existing tools for screening for gender-based violence have been mostly formulated in the context of developed countries. This paper assesses which violence screening tools designed for use as the primary health care level would be feasible for use in Afghanistan and Pakistan, countries characterized by limited resources, unsupportive institutional frameworks and gender and social norms that reinforce domestic violence. A systematic review was made of the literature to evaluate the different screening instruments. The Women's Experience with Battering Scale (short version) and the Ongoing Violence Assessment Tool were judged to be the most useful tools for screening for violence against women in Afghanistan and Pakistan because they are short, easy to administer and to score and respond to health care provider identified barriers of time and knowledge constraints for conducting screening for intimate partner violence.

Instruments de dépistage de la violence sexiste efficaces pour une utilisation en soins de santé primaires en Afghanistan et au Pakistan : une revue systématique

RÉSUMÉ Les prestataires de soin de santé ont un rôle important à jouer dans la prévention de la violence à l'encontre des femmes et la réponse à apporter. Toutefois, les instruments existants pour le dépistage de la violence sexiste ont principalement été formulés dans le cadre des pays développés. Le présent article évalue les instruments conçus pour un dépistage en soins de santé primaires qui pourraient être utilisés en Afghanistan et au Pakistan, pays caractérisés par des ressources limitées, des structures institutionnelles peu coopératives et des normes sociales et relatives aux sexes renforçant la violence domestique. Une revue systématique de la littérature a été menée afin d'évaluer les différents instruments de dépistage. La version abrégée de l'échelle Women's Experience with Battering Scale et l'instrument Ongoing Violence Assessment Tool ont été estimés être les outils les plus utiles au dépistage de la violence à l'encontre des femmes en Afghanistan et au Pakistan. En effet, ils sont courts, faciles à administrer et à noter et tiennent compte des obstacles identifiés par les prestataires de soins comme les contraintes de temps et de connaissances pour réaliser un dépistage de la violence exercée par le partenaire intime.

${ }^{I}$ Gender in Health and Development Unit, World Health Organization, Regional Office for the Eastern Mediterranean, Cairo, Egypt (Correspondence to J. Vogel: vogelj@emro.who.int).

Received: 05/10/11; accepted: 26/01/12 


\section{Introduction}

Health providers often serve as the first point of contact with survivors of domestic violence and have an important role to play in prevention and response to violence against women. The screening tools and recommended interventions for response from the health care sector have largely been formulated in the developed world in the presence of institutional frameworks that provide at least some level of support for survivors of domestic violence. The question is whether the available screening tools used in primary care settings would be feasible in the different sociocultural contexts of Pakistan and Afghanistan, countries characterized by limited resources, unsupportive institutional frameworks and gender and social norms that reinforce domestic violence.

Potential barriers to their use must be considered in the selection of optimal screening tools for the primary health sector. In studies outside the Eastern Mediterranean Region health care providers have cited a number of barriers to routine screening for domestic violence, including lack of knowledge about violence against women, concern over the lack of effective referral options, lack of time and fear of offending patients $[1,2]$. The limited amount of time in a typical consultation and providers' lack of awareness of violence against women were also perceived by patients as barriers to disclosing violence $[2,3]$.

The aim of this study was to conduct a systematic review of screening instruments for primary health care response to violence against women in order to identify domestic violence screening tools suitable for application in Afghanistan and Pakistan. A literature review was also conducted to identify the cultural conditions that might impede use and/or acceptance of screening tools, both by health care providers and the community.

\section{Methods}

\section{Database searches}

The databases of Academic Premier, Cochrane Library, PubMed, Popline and the World Health Organization (WHO) Index Medicus for the Eastern Mediterranean Region were searched for relevant studies published from the year 2000-10. Studies were included if they related to health sector response to violence against women or intimate partner violence and were linked specifically to primary care entry points. Databases were searched using various combinations of $\mathrm{MeSH}$ terms (domestic violence, diagnosis and primary health care) and keywords were grouped according to the different themes being assessed for the study. Domestic violence searches included keywords "intimate partner violence", "spouse abuse" and "domestic violence". "Diagnosis", "response", "screening" and "prevention and control" were used to indicate interventions by the health sector. "Primary health care", "first level health care", "family based practice" or "women's health" were used to designate primary health care as entry points for interventions. "Evaluation", "assessment", "review" and "meta-analysis" were used to indicate evaluations of health sector interventions on violence against women. The best combination of terms for yielding relevant articles were domestic violence, violence against women, women's health, screening, diagnosis and primary health care. In addition, the keywords "Afghanistan" and "Pakistan" were used in combination with MeSH or keywords "violence against women" or "women's health" to find studies relating to the focus of this paper. Additional studies were retrieved by reviewing reference lists of the relevant studies found in the database searches or related articles listed in PubMed. The titles and abstracts of all eligible studies were screened for the inclusion criteria and retrieved if deemed relevant. In order to understand the institutional readiness of the health sector to accommodate various screening parameters the legal frameworks concerning violence against women were reviewed through the United $\mathrm{Na}$ tions Secretary-General's database on violence against women [4-6].

\section{Inclusion and exclusion criteria}

The inclusion criteria included primary diagnostic studies that described one or more screening instruments on domestic violence currently being used globally and whose point of entry was primary health care, first level health care, family based practice or women well care. Studies were required to assess the benefits and drawbacks of one or more screening instruments on domestic violence. Secondary studies (meta-analysis, systematic reviews or guidelines) that reviewed screening instruments, including any in Afghanistan and Pakistan, were also retrieved.

Exclusion criteria included content related only to causes or outcomes of violence against women and content relating only to secondary or tertiary health care response to violence against women. In addition, studies were excluded when the content related exclusively to abuse of children, the elderly or men. Studies that were not published in English, were not available to the researcher in the full text, were not published in a peer-reviewed journal or were published before the year 2000 were also excluded.

\section{Review criteria}

Studies were assessed for quality, based on intrinsic factors of whether the aims were clearly and logically specified, the methodology was appropriate to the aims and if the study populations were well defined. Studies meeting both the selection criteria and the intrinsic quality review were then subjected to more specific review criteria. Modified versions of the Critical Appraisal Skills Programme (CASP) guided the process 
of critically appraising the diagnostic test studies and systematic reviews [7]. Studies were assessed based on the number of affirmative responses to the modified CASP criteria and classified into ratings of good, fair or poor.

\section{Ethical considerations}

The project did not involve any live subjects and as such had no ethical implications.

\section{Results}

\section{Cultural context of intimate partner violence}

\section{Search results}

A total of 27 articles were located in order to review the sociocultural background to violence against women in Afghanistan and Pakistan. Of these 20 were eliminated on in-depth review due to absence of reference or relevance to violence against women and its cultural context. The 7 studies used in the review relating to sociocultural characteristics specific to Afghanistan and Pakistan had clear aims and appropriate methodologies [8-14]. The study populations were well-defined but weaknesses were found in sample justifications. The studies were primarily qualitative so generalization to the larger populations of Afghanistan and Pakistan was limited but they did include representation of the majority of ethnic groups and different socioeconomic levels.

\section{Legislative environment}

The lack of legal support systems for women has been cited by health professionals in Pakistan as a barrier to responding to domestic violence in patients and therefore bears consideration in the discussion on compatibility of screening instruments [10]. A review of the UN Secretary-General's database on violence against women revealed that legislation concerning all forms of violence has increased in recent years in both Afghanistan and Pakistan. Services, however, are still largely absent for women facing violence, and pertain mostly to legal advice in a small number of shelters and/or counselling services [4].

\section{Sociocultural context}

Existence of cultural traditions such as early marriages, exchange marriages and marriages with conditional bride pricing, as cited in Hyder et al. [8], are indicators of gender inequality which limit the decision-making powers of women and increase their vulnerability to violence. In the context of traditional harmful attitudes and practices towards gender equality, the family domain is often viewed as private and beyond the jurisdiction of institutions. This implies an environment in which health provider involvement in enquiring about domestic violence would be interpreted as an unacceptable intrusion into family affairs. Indeed, health workers treating Afghani refugees in Pakistan reported that domestic violence should be addressed and resolved privately in the family and not be addressed by the health sector [8]. Descriptions of social norms on family, marriage and women in Afghanistan and Pakistan were similar across the 7 articles reviewed.

Khan and Hussain found that disclosure of intimate partner violence to health care providers was inhibited by fear of ruining izzat (family honour) [9]. Disclosure to anyone outside the family and separation from the husband, or particularly divorce, were perceived as bringing shame on the family. Van Egmond et al's study reported that $89 \%$ of the Afghani women sampled had to seek their husband's approval to use health services, and this also had implications for women's autonomy and ability to disclose violence to health care providers [11].

A theme of socially predicated acceptance of abuse in marriage recurred in several of the studies. Husband abuse was cited as the "norm" by women sampled in 2 of the studies from Pakistan $[11,14]$. Similarly, in Afghanistan, 50\% of women in Van Egmond et al.'s study believed that the husband had the right to beat his wife when she disobeys him and $75 \%$ felt that sex, whether consensual or not, was a married woman's duty [11]. These norms impact levels of disclosure by women and responses to intimate partner violence by both patients and health care providers.

In terms of identifying health sector barriers to conducting screening and response to domestic violence in Afghanistan and Pakistan, there were few data available to extract from the literature review. Only when there were severe cases of abuse against women did health care providers report initiating actions beyond a purely medical response, for example by involving local authorities or nongovernmental organizations (NGOs) known to be working in human or women's rights [8]. Fikree et al.'s study found that Pakistani obstetricians cited barriers due to insufficient time during consultations, unawareness of referral resources for intimate partner violence, fear for patient's safety upon disclosure, inability to help the situation and fear of police involvement [12].

\section{Screening instruments for intimate partner violence}

\section{Search results}

A total of 53 articles passed the inclusion criteria for diagnostic tests for screening for intimate partner violence based on title and abstract review, including cross-checking references of retrieved articles. Of these, 37 studies were eliminated on closer investigation, primarily for their focus on emergency rooms/ departments, intimate partner violence during pregnancy, intimate partner violence interventions not originating from primary health sector locations, focus on child/elderly violence, focus on intimate partner violence outcomes and prevalence or focus on intimate partner violence research methodology. Of the remaining 16 papers 5 studies were not available in the full text, leaving a total of 11 studies which passed the 
selection criteria for diagnostic tests of screening instruments for violence against women in a primary health care setting, 3 of which were meta-analyses. Of those, 8 studies rated well in the CASP-guided critical appraisal, 2 rated fair and 1 rated poor (Tables 1 and 2) [15-25]. The findings of the poorly rated study [23] were not considered in the recommendations of optimal screening tools for Afghanistan and Pakistan.

\section{Screening instruments}

The screening instruments included in the review were the Hurt, Insult, Threaten, Scream (HITS), the Woman Abuse Screening Tool (WAST), the Women's Experience with Battering Scale (WEBS), the Index of Spouse Abuse-Physical Scale (ISA-P), the Ongoing Violence Assessment Tool (OVAT) and the Humiliation, Afraid, Rape, Kick (HARK).

The HITS is a 4-item scale that screens for physical violence while the WAST is an 8-item scale that measures physical, sexual and emotional abuse occurring within the previous 12 months $[15,26,27]$. There is also a modified WAST called the WAST Short (WAST-S) which contains 2 items from the WAST and measures the amount of tension in a relationship and how difficult it is to resolve arguments on a scale of $1-3[15,26,27]$. The advantages of HITS are that it has been tested on diverse populations and has been used successfully in primary health care settings [26,27]. Its success with diverse populations reflects its compatibility across cultures and this has positive implications for its use in Afghanistan and Pakistan. The advantages of WAST are that it measures physical, sexual and emotional abuse. In addition women have reported comfort in using it [15]. Considering the sensitivities involved in discussing violence in Afghanistan and Pakistan, the ease of use and positive response by female survivors of violence to the WAST is important. WAST was also used as a criterion standard to test HITS and WAST-S.

Brown et al. found good internal consistency in the WAST and a positive response from both physicians and patients in using it, although patients screening positive were less comfortable with the items on physical and sexual abuse, contrary to more positive patient reactions cited in Wathen et al. $[15,16]$. MacMillan et al. calculated the WAST as having a sensitivity of $47 \%$ and specificity of $95.6 \%$, using the Composite Abuse Scale (CAS) as the criterion standard [17]. The CAS is a validated 30-item research instrument with 4 subscales measuring severe combined abuse, emotional abuse, physical abuse and harassment [15]. Wathen et al. found a better sensitivity in the WAST (88\%) and a lower specificity (89\%). also using the CAS as the criterion and a randomized control trial design [15]. Chen et al. found positive attributes in the WAST-S in terms of physician and patient comfort with the instrument, scoring Cronbach alpha of 0.95 and 0.97 respectively [19]. They also found that physicians preferred the WAST-S over the HITS and WAST because it is a shorter instrument and was easier to administer. Brevity and ease of administration are important variables to consider because time constraints and lack of capacity faced by providers in Afghanistan and Pakistan [12]. In Rabin et al.'s systematic review to determine the strength of psychometric properties of intimate partner violence screening instruments, they found both WAST and WAST-S had good internal reliability and acceptable concurrent validity in differentiating abused from non-abused patients [18].

Chen et al. reported good sensitivity and specificity for the HITS, both in the English version (86\% and 99\% respectively, with a cut-off score of 10.5) and the Spanish version (100\% and $86 \%$ respectively, with a cut-off score of 5.5) [19]. The different cut-off scores reflect adaptations based on conceptual language differences in interpretation between the Spanish and English languages, and indicates that optimal cut-off scores as well as construct verifications would need to be determined for other languages it is translated into. Feder et al.'s review of 29 diagnostic studies completed through 2006 verified HITS performance in both English and Spanish, finding that HITS ranked the highest among screening instruments for violence against women and that it had good diagnostic accuracy [20]. Nelson et al.'s review of 14 studies completed in 2002 found that HITS had varying sensitivity depending on the target population, for example it had lower sensitivity in men than women, but it did seem to have good internal reliability and concurrent validity [25]. However, HITS does not determine sexual abuse or ongoing violence, which are important variables for inclusion in screening in Afghanistan and Pakistan.

Another instrument that was tested in the diagnostic studies was the WEBS, which is a 10-item screening instrument that measures psychological battering in addition to physical abuse [27]. High incidents of verbal abuse cited in studies on violence in Afghanistan and Pakistan render this an important measurement variable for screening use in these 2 countries $[13,14]$. Coker et al. did a cross-sectional survey to determine whether the WEB or the Index of Spouse Abuse-Physical Scale (ISA-P) was more sensitive for detecting mental and physical outcomes of intimate partner violence [21]. The authors found good agreement between the ISA-P and WEBS (Pearson correlation coefficient $r=0.67)$ and found that WEBS scores were significantly more likely to be associated with poor mental health, anxiety, depression, drug abuse, post-traumatic stress disorder and low social support than the ISA-P, which was found to associate better with domestic violence related physical injuries [21]. Feder et al.'s systematic review also reported positive findings for the 


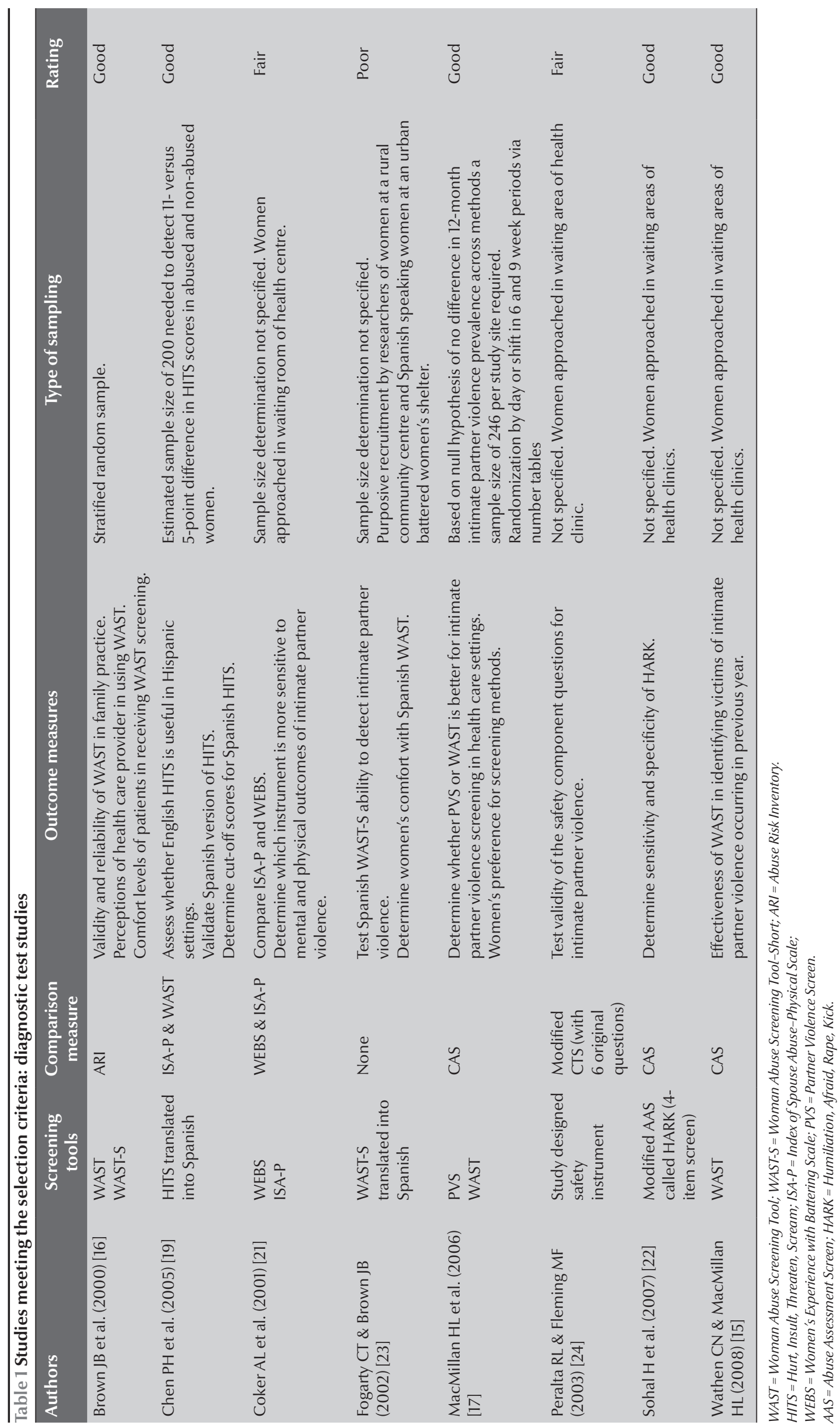




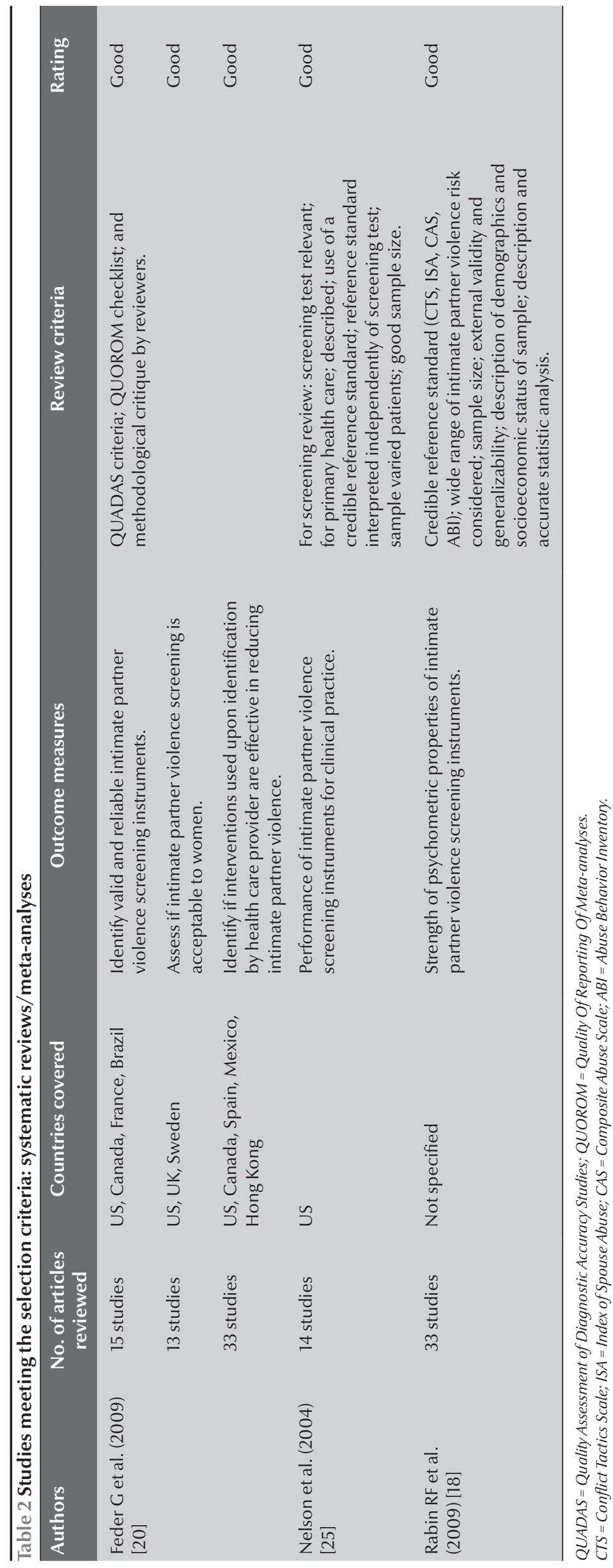

WEBS, ranking it as the second best domestic violence screening instrument and as having good concurrent validity and reasonable bias [20]. The authors cited that the drawback of the WEBS was that it did not identify acts of abuse or link emotional impacts to abuse.

The same systematic review found that the OVAT ranked third best as a screening instrument for domestic violence [20]. OVAT is a 4-item tool that detects existing abuse. The authors found that the OVAT had good predictive power and reasonable reliability and was quick to administer and score, taking only 1 minute in total. This is an attractive feature for Afghanistan and Pakistan, which are low-resource settings with limited to no experience in screening for domestic violence.

Another user-friendly violence against women screening instrument that was found to have good sensitivity (81\%) and specificity (95\%) was the HARK $[19,22]$. This is a 4-item screen modified from the Abuse Assessment Screen (AAS) which is a 5-item screen that detects abuse in pregnant women. The focus of this discussion, however, is not on detection of violence during pregnancy.

\section{Discussion}

The WAST-S or the OVAT would be the most feasible screening instruments for use in Afghanistan and Pakistan because they are short, easy to administer and score. The OVAT has an advantage of being able to detect existing abuse and takes only 1 minute to administer, which would address barriers of time cited by health care providers in Pakistan [12]. Ease of administration is an important variable to address in view of the knowledge constraints of health providers in screening for intimate partner violence.

The presence of legislation is not sufficient to establish cultural compatibility of screening tools. The social environment and potential acceptance or rejection of screening instruments must also be considered. Services to which women can be 
referred must be available once violence has been identified. A lack of services available for women facing violence is a concern, and has been raised by health care providers as a barrier to response. The lack of services in Afghanistan and Pakistan was confirmed in the UN Secretary General's database on violence against women. There are few socially acceptable options for women in these countries other than to endure the violence. Divorce is usually not considered as an option because it carries a negative social stigma, will bring shame on the family and may reduce family support to the woman. It is not socially acceptable for women to live alone so they are dependent on their family's support, especially if they are unemployed or without other income options [9].

While the WAST-S or the OVAT screening instruments respond to health provider challenges of time and lack of capacity, they cannot address the sociocultural barriers of acceptance of violence, containment of violence to the privacy of the family domain and the resultant few options/services women have while suffering violence. Routine screening of domestic violence is not yet advisable in Afghanistan and Pakistan. Selective inquiry, however, would be reasonable in the current context, for example by screening women presenting consistently with undefined pains and stomach complaints, presenting repeatedly with injuries and presenting with anxiety or depression [28]. Either the WAST-S or the OVAT would be useful screening tools in selective inquiry cases, but must of course be combined with training for health care providers on identification of suspicious symptoms and appropriate administering of the screening tools, combined with training on appropriate provider-patient communication styles for responding to victims of domestic violence.

\section{Limitations/future research}

While more than $95 \%$ of the articles identified were accessible, it may be that the 5\% not accessible could have provided information contrary to data that was extracted from the enlisted studies or could have served to further strengthen conclusions made.

Future research would benefit from analysis of resource requirements of the recommended interventions and assessment of target country resource capacities, both financial and human. The issue of transference of concepts from existing intimate partner violence screening tools into the languages of the target countries should also be considered. Additional data on the sociocultural contexts of the target countries needs greater focus in future research, perhaps via secondary data from NGOs working at country level and if possible, focus group discussions with target groups. Proposals for a feasible primary health care response would benefit from integration and consideration of these variables.

\section{Conclusion}

Among the domestic violence screening tools popular in developed country settings such as the United States and the United Kingdom, the OVAT or the WAST-S appear the most feasible instruments for the contexts of Afghanistan and Pakistan. Disclosure in the best of circumstances is a difficult process and in Afghanistan and Pakistan disclosure is made even more difficult by pervasive sociocultural norms that value preservation of the family unit over the preservation of the individual. Compassionate and sensitive responses by health care providers will help cross the disclosure barriers and use of the OVAT or the WAST-S may be helpful to health care providers in their limited time and capacity in responding to domestic violence.

\section{References}

1. Jaffee KD et al. Physician-identified barriers to intimate partner violence screening. Journal of Women's Health, 2005, 14:713-720.

2. Bacchus L, Mezey G, Bewley S. Experiences of seeking help from health professionals in a sample of women who experienced domestic violence. Health and Social Care in the Community, 2003, 11:10-18.

3. Hathaway J, Willis G, Zimmer B. Listening to survivors' voices: addressing violence against women in the health care setting. Violence Against Women, 2002, 8:687-719.

4. UN Secretary-General's database on violence against women [website] http://sgdatabase.unwomen.org/home.action, accessed 24 December 2012).

5. Country pages. Afghanistan. UN Secretary-General's database on violence against women [website] (http://sgdatabase.unwomen.org/countrylnd.action? countryld=101, accessed 24 December 2012).

6. Country pages. Pakistan. UN Secretary-General's database on violence against women [website] (http://sgdatabase.un- women.org/countrylnd.action?countryld=997, accessed 24 December 2012).

7. Making sense of evidence. Critical Appraisal Skills Programme (http://www.casp-uk.net/, accessed 24 December 2012).

8. Hyder AA, Noor Z, Tsui E. Intimate partner violence among Afghan women living in refugee camps in Pakistan. Social Science and Medicine, 2007, 64:1536-1547.

9. Khan A, Hussain R. Violence against women in Pakistan: Perceptions and experiences of domestic violence. Asian Studies Review, 2008, 32:239-253.

10. Rabbani F, Qureshi F, Rizvi N. Perspectives on domestic violence: case study from Karachi, Pakistan. Eastern Mediterranean Health Journal, 2008, 14:415-426.

11. Van Egmond $\mathrm{K}$ et al. Reproductive health in Afghanistan: results of a knowledge, attitudes and practices survey among Afghan women in Kabul. Disasters, 2004, 28:269-282.

12. Fikree FF et al. Pakistani obstetricians' recognition of and attitude towards domestic violence screening. International Journal of Gynaecology and Obstetrics, 2004, 87:59-65. 
13. Ali TS, Bustamante-Gavino I. Prevalence of and reasons for domestic violence among women from low socioeconomic communities of Karachi. Eastern Mediterranean Health Journal, 2007, 13:1417-1426.

14. Shaikh Ali M. Is domestic violence endemic in Pakistan: perspective from Pakistani wives. Pakistan Journal of Medical Sciences, 2003, 19:23-28.

15. Wathen $\mathrm{CN}$, Jamieson E, MacMillan $\mathrm{HL}$; McMaster Violence Against Women Research Group. Who is identified by screening for intimate partner violence? Women's Health Issues, 2008 , 18:423-432.

16. Brown JB et al. Application of the Woman Abuse Screening Tool (WAST) and WAST-short in the family practice setting Journal of Family Practice, 2000, 49:896-903.

17. MacMillan HL et al. Approaches to screening for intimate partner violence in health care settings: a randomized trial. Journal of the American Medical Association, 2006, 296:530-536.

18. Rabin RF et al. Intimate partner violence screening tools: a sysi tematic review. American Journal of Preventive Medicine, 2009 36(5):439-445

19. Chen $\mathrm{PH}$ et al. Screening for domestic violence in a predominantly Hispanic clinical setting. Family Practice, 2005, 22:617-623.

20. Feder $\mathrm{G}$ et al. How far does screening women for domestic (partner) violence in different health-care settings meet criteria for a screening programme? Systematic reviews of nine UK
National Screening Committee criteria. Health Technology Assessment, 2009, 13(16).

21. Coker AL et al. Assessment of clinical partner violence screening tools. Journal of the American Medical Women's Association, 2001, 56:19-23.

22. Sohal H, Eldridge S, Feder G. The sensitivity and specificity of four questions (HARK) to identify intimate partner violence: a diagnostic accuracy study in general practice. BMC Family Practice, 2007, 8:49.

23. Fogarty CT, Brown JB Screening for abuse in Spanish-speaking women. American Board Family Practice. 2002, 15(2):101-111.

24. Peralta RL, Fleming MF Screening for intimate partner violence in a primary care setting: the validity of "feeling safe at home" and prevalence results. Journal of the American Board of Family Practice, 2003, 16(6):525-532.

25. Nelson HD et al. Screening women and elderly adults for family and intimate partner violence: a review of the evidence for the US Preventive Services Task Force. Annals of Internal Medicine, 2004, 140:387-396.

26. Chen $\mathrm{PH}$ et al. Randomized comparison of 3 methods to screen for domestic violence in family practice. Annals of Family Medicine, 2007, 5:430-435.

27. Punukollu M. Domestic violence: screening made practical. Journal of Family Practice, 2003, 52:537-543.

28. Domestic violence: a resource manual for health care professional. London, United Kingdom Department of Health, 2000 